\title{
Uiolência e privação de liberdade: um estudo sobre trajetórias juvenis a partir do Radar de Relações Interpessoais
}

\author{
Uiolencia y privación de libertad: un estudio sobre trayectorias juveniles a partir \\ del Radar de Relaciones Interpersonales \\ Uiolence and the Confinement in an Educational Facility: A Study about the \\ Trajectory of Young Offenders Based on the Radar of Interpersonal Relationships
}

\author{
Maria Claudia Santos Lopes de Oliveira* \\ Instituto de Psicologia \\ Kelita Rejanne Machado** \\ Instituto de Psicologia
}

Doi: http://dx.doi.org/10.12804/revistas.urosario.edu.co/apl/a.7966

\section{Resumo}

A psicologia cultural é um ramo da psicologia que constitui fértil matriz interpretativa para sustentar o trânsito analítico entre o macrocontexto histórico-cultural e institucional, e o microcontexto das relações interpessoais, a fim de se compreender, desde uma perspectiva idiográfica, a configuração de trajetórias de desenvolvimento de adolescentes autores de ato infracional. Discutimos três estudos de caso decorrentes de nove meses de imersão etnográfica, durante a qual foram utilizados diferentes dispositivos metodológicos para favorecer a construção de narrativas e representações gráficas das trajetórias de vida. No presente artigo, exploraremos um dos instrumentos, denominado Radar de Relações Interpessoais (RRI).
Os resultados produzidos pelo RRI apontam que as medidas socioeducativas não promovem a ressocialização dos jovens, despreparam-nos para a participação social e contribuem para afastá-los das redes significativas previamente existentes. Por outro lado, o apoio recebido de diferentes atores institucionais foi percebido como promovendo tênue proteção, que deixa de existir quando são liberados. A existência de Outros significativos, catalisadores de trajetórias saudáveis e da projeção de futuros possíveis dentro e fora da internação, foi percebido como importante para o alcance de trajetórias de desenvolvimento desvinculadas da infração.

Palavras-chave: desenvolvimento humano, justiça juvenil, psicologia semiótico-cultural, Radar de Relações Interpessoais, trajetórias juvenis.

\footnotetext{
* Dirigir correspondencia a Maria Claudia Santos Lopes de Oliveira, Departamento de Psicologia Escolar e do Desenvolvimento, Campus Darcy Ribeiro, ICC Sul. Correio eletrônico: mcsloliveira@gmail.com; claudia@unb.br

** Departamento de Psicologia Escolar e do Desenvolvimento, Campus Darcy Ribeiro, ICC Sul.
}

Para citar este artigo: Lopes de Oliveira, S. M. C., \& Machado, R. K. (2019). Violência e privação de liberdade: um estudo sobre trajetórias juvenis a partir do Radar de Relações Interpessoais. Avances en Psicología Latinoamericana, 37(3), 307-325. Doi: http://dx.doi.org/10.12804/revistas.urosario.edu.co/apl/a.7966 


\section{Resumen}

La psicología cultural es una rama de la psicología que constituye una fértil matriz interpretativa para sustentar el tránsito analítico entre el macro contexto histórico-cultural e institucional, y el micro contexto de las relaciones interpersonales, con el fin de comprenderlo desde una perspectiva idiográfica, la configuración de trayectorias de desarrollo de adolescentes autores de acto infractor. Discutimos tres estudios de caso resultantes de nueve meses de inmersión etnográfica, durante la cual fueron utilizados diferentes dispositivos metodológicos para favorecer la construcción de narrativas y representaciones gráficas de las trayectorias de vida. En el presente artículo, exploraremos uno de los instrumentos, denominado Radar de Relaciones Interpersonales (RRI). Los resultados producidos por el RRI apuntan a que las medidas socioeducativas no promueven la resocialización de los jóvenes, no nos preparan para la participación social y contribuyen para alejarlos de las redes significativas previamente existentes. Por otro lado, el apoyo recibido de diferentes actores institucionales fue percibido como promoviendo tenue protección, que deja de existir cuando son liberados. La existencia de Otros significativos, catalizadores de trayectorias saludables y de la proyección de futuros posibles dentro y fuera de la internación, fue percibido como importante para el alcance de trayectorias de desarrollo desvinculadas de la infracción.

Palabras clave: desarrollo humano, justicia juvenil, psicología semiótico-cultural, Radar de Relaciones Interpersonales, trayectorias juveniles.

\section{fibstract}

Cultural psychology is a branch of general psychology and it represents an important interpretative matrix that supports the analytical transit between the historical-cultural/institutional macro-context and the micro-context of interpersonal relations, in order to understand, from an idiographic perspective, the (trans)formation of developmental trajectories of juvenile offenders in the flux of irreversible time. We discuss in this article three case studies analyzed during nine months of ethnographic immersion, in which participants used different methods to evoke narratives and graphic representations of life trajectories. We explore here the Interpersonal Relations Radar (RRI). The results produced by the RRI indicate that, against the legal proposition, socio-educational measures do not (re)socialize young people, they also turn them unprepared for social participation and reduce significant networks previously existing around them. On the other hand, participants perceived the support provided bydifferent institutional actors as a source of protection, yet a weak one, which ceases to exist when the offenders are released. Thus, the existence of significant others that are seen as sources of social identification, leading the young people towards healthy trajectories and the projection of different futures, was something perceived as important for the achievement of developmental trajectories distant from the infraction. Keywords: Human development, Interpersonal Relations Radar, juvenile justice, semiotic-cultural psychology, youth trajectories

O interesse deste artigo é o estudo da configuração de trajetórias biográficas juvenis desde uma perspectiva de investigação do desenvolvimento pela primeira autora e colaboradores, que visa aprimorar o trânsito analítico entre o micro e o macrocontexto dos fenômenos psicológicos, ou seja, integrar no mesmo quadro de análise as dimensões pessoal, interpessoal/relacional e cultural. Nossa abordagem adota o paradigma cultural semiótico na aproximação aos fenômenos psicológicos e concilia dois eixos de elaboração teórica a ele relacionados: a teoria do sistema de self dialógico (TSSD) e o estudo de trajetórias

Da primeira, tomamos a centralidade do conceito de self e a importância de concebê-lo de forma sistêmica e interdependente da alteridade; nos estudos de trajetórias, identificamos uma possível unidade de análise do desenvolvimento humano, 
sendo este entendido como a construção temporal e dinâmica do senso de si. Tendo como pano de fundo o paradigma semiótico, podemos pensar o self como signo e também explorar a generatividade psicológica da particular relação entre signos culturais e sentidos pessoais na constituição do self e na prospecção imaginária de futuros, que se expressam em histórias narradas pelo sujeito. Nesse sentido, a contribuição que o artigo visa prover à psicologia cultural é teórica e metodológica. No que se refere à contribuição teórica para o estudo do desenvolvimento humano, implica na articulação entre o olhar sistêmico, oferecido pela TSSD, e uma mirada processual, possibilitado pelo conceito de trajetória de vida.

Assim, partimos de um estudo idiográfico realizado pela segunda autora (Machado, 2018), em que se produziram três estudos de caso longitudinais protagonizados por jovens com o seguinte perfil: vivem em condição aguda de pobreza e exclusão social; envolveram-se em ato(s) infracional(is) quando menores de 18 anos; cumpriram medida socioeducativa de internação e, nos três últimos meses dessa medida, foram transferidos para uma mesma unidade, na qual passaram a ter o benefício de saídas sistemáticas, para fazer cursos profissionalizantes e trabalhar, sem o acompanhamento de agentes de segurança. Dos três casos, trazemos aqui os resultados de um dos instrumentos utilizados no estudo principal, o Radar de Relações Interpessoais (RRI), que nos parecem bastante fecundos para subsidiar as discussões aqui almejadas.

\section{Psicologia cultural semiótica e a abordagem do desenvolvimento humano}

No processo histórico e político da formação das ciências humanas e sociais, cultura e subjetividade haviam se divorciado, tornando-se partes de campos científicos distintos (Sato \& Valsiner, 2010). Ao trazer o conceito de cultura para dentro do debate dos processos psicológicos, a psicologia cultural semiótica destaca a importância dos processos de significação como instrumentos de mediação da relação dos sujeitos com o mundo. Nesse sentido, o sujeito é encarado como um ser que constrói sua existência, a partir da ação sobre a realidade, com o objetivo não apenas de satisfazer suas necessidades, mas de criar constantemente novas necessidades, tendo por motor as características humanas de intencionalidade, afetividade e motivação (Branco \& Valsiner, 2010). A base deste processo seria a reconstrução interna das atividades socialmente enraizadas e historicamente construídas, mediante as operações com signos, chegando-se ao ponto de se identificar as propriedades objetivas da realidade e de tornar a si mesmo objeto de reflexão. Tratamos a seguir de dois tópicos que se desdobram da Psicologia Cultural Semiótica, importantes para o desenho dos argumentos e análises apresentadas na sequência: a Teoria do Sistema de Self Dialógico (TSSD) e a contribuição dos estudos sobre trajetórias de vida.

\section{Teoria do Sistema de Self Dialógico}

O conceito de self passou por várias formas de compreensão em Psicologia tendo sido relacionado, conforme a base teórica, a conceitos como personalidade e ego, em referência a uma estância interna ao sujeito. De acordo com essas bases teóricas, o self se caracterizaria como um fenômeno cognitivo, definido como o autoconceito ou a autorrepresentação. A nosso ver, trata-se de uma concepção individualista e autocontida do self, que desconsidera a cogênese de sujeito e contexto e a intencionalidade do próprio sujeito, que se reorganiza interna e externamente na relação com o outro e com a cultura (Lopes de Oliveira, 2006, 2014; Salgado \& Gonçalves, 2007).

No campo dos estudos psicológicos contemporâneos, há uma crescente preocupação com a construção de modelos teóricos voltados à compreensão da totalidade da pessoa em desenvolvimento no tempo irreversível, não limitados ao enfoque de comportamentos ou funções mentais pretensamente 
isolados e estáticos. Entre os esforços mais criativos nessa direção, o conceito de sistema de self dialógico-SSD (Freire \& Branco, 2016) aprimora o conceito de self dialógico proposto por Hermans e colaboradores (Hermans, Kempen \& Van Loon, 1992, Valsiner, 2016). De acordo com a TSSD, o self é um sistema dinâmico e aberto, constituído por uma multiplicidade de posições subjetivas em relação, que se formam e transformam no fluxo irreversível do tempo. O SSD desenvolve-se com base no histórico de ininterruptas relações que se dão no próprio sujeito (entre posições do eu), entre sujeitos (sujeito-outro) e deles com a cultura (Branco, Freire, \& Roncancio-Moreno, no prelo; Lopes de Oliveira \& Guimarães, 2016). Ademais, cada posicionamento inclui duas dimensões interdependentes: a do 'Eu' que age no mundo e a do 'Me' que produz significados sobre o agir. Essa segunda dimensão, em especial, depende da adoção de uma dimensão reflexiva, a de terceira pessoa, fazendo do próprio agir objeto de escrutínio e de produção de significados. A unidade dialógica entre essas duas dimensões aplicadas a todas as possíveis posições do Eu, em um dado momento do curso de vida, contribui para a gênese de um senso de continuidade da pessoa no tempo e no espaço.

No diagrama representativo do sistema de self estão incluídos os seguintes elementos interrelacionados: as posições do self (I/self positions), subdivididas em posições internas (inner positions) e externas (outer positions), e alteridades, ou seja, pessoas e contextos externos ao self que, no processo histórico, tendem a ter papel determinante na configuração do sistema de self de uma pessoa. Antevemos que este artigo possa contribuir com o olhar para a relação sistêmica entre posições externas/alteridades e o desenvolvimento do self. Para isso, recorremos ao conceito de esferas de experiência (Valsiner, 2012). Esferas de experiência são contextos semióticos partilhados entre integrantes de determinado grupo, cujas condições culturais singulares participam na constituição das subje- tividades particulares dos integrantes do grupo. Nelas são promovidas interações semioticamente mediadas entre o sujeito e a realidade física, social e cultural, no fluxo irreversível do tempo (Valsiner, 2012). Os estudos de caso que serão explorados adiante abordam o desenvolvimento dos adolescentes tendo como cenário uma esfera principal, a unidade de saída sistemática - unidade de internação frequentada pelos três participantes da pesquisa. Interessou-nos este contexto por caracterizar-se como transitório, de passagem por proporcionar ao adolescente a transição objetiva e/ ou semiótica entre distintas condições normativas (interno/não-interno), espaciais (dentro e fora do sistema socioeducativo) e temporais (antes/depois de ganhar liberdade). A diversificação das esferas de experiência humana favorece a incorporação ao sistema de self de novos posicionamentos, o que significa expansão e maior integração hierárquica do self.

\section{O estudo de trajetórias}

Para a psicologia moderna, o desenvolvimento humano ocorreria de acordo com uma sequência de estágios de crescente complexidade, em que cada um serviria de base para o seguinte, seguindo um caminho unidirecional e linear. Assim sendo, o olhar sobre o fenômeno do desenvolvimento estaria impregnado de concepções dualistas, monistas e taxonômicas, em que o desenvolvimento de todos seguiria uma via única, do individual ao social e do biológico ao societal. No cenário contemporâneo da psicologia do desenvolvimento, nota-se uma concentração de esforços no sentido de prover outros modelos interpretativos que alimentem criticamente esse campo do saber (Abbey \& Diriwächter, 2008; Zittoun, Valsiner, Vedeler, Salgado, Gonçalves \& Ferring, 2013; Bertau, Gonçalves \& Raggatt, 2013). Para tanto, as pesquisas, práticas e teorias têm tentado ultrapassar os modelos teóricos da psicologia moderna, ao introduzir concepções que enfatizem a natureza 
relacional, mediada, dialógica e contextual dos processos de constituição dos sujeitos ao longo de suas trajetórias de vida.

A origem do conceito de trajetória provém dos estudos de Glenn Elder (1985), Daaleman e Elder (2007) sobre desenvolvimento humano no curso de vida. De acordo com os trabalhos originais de Elder e colaboradores, os princípios centrais do paradigma do curso de vida são: (a) substituição do modelo de fases de desenvolvimento pelo de desenvolvimento contínuo; (b) ênfase na ideia de curso de vida, (c) compreensão processual do desenvolvimento humano, que se estende do nascimento à morte; (d) foco na ação humana, considerando-se os sujeitos como agentes de seu desenvolvimento; (e) referência ao espaço-tempo, ao contexto que delimita a ação; e, por fim, (f) defesa de que ninguém se desenvolve sozinho, valorizando-se, portanto, a ideia de que somos parte de uma trama de relações socioculturais.

Deve-se ressaltar, no entanto, que para Elder a noção de trajetória ainda carrega um caráter linear, caminho percorrido no passado, o qual cria as condições para o presente e o futuro. Assim como para Gotlieb e Wheaton (1997), para quem a concepção de trajetória reporta à tendência em persistir nos mesmos esquemas e padrões, ao longo do curso de vida. Percebe-se que, tanto na primeiro como na segunda abordagem, falta uma visão dinâmica das trajetórias humanas como processos em permanente reconstrução, assim como dotadas de orientação ao futuro, compreensão aqui adoada, seguindo a abordagem da equifinalidade de trajetórias (Sato \& Valsiner, 2010; Sato \& Tanimura, 2016).

Ao tratarmos de self e trajetórias de vida, o papel da temporalidade é uma dimensão importante a ser destacada. Nesse caso, o tempo não é entendido como movimento linear, homogêneo e unidimensional, medido pelo intervalo entre duas posições dos ponteiros do relógio. Esta perspectiva diversa permite que o sujeito se transforme ao transitar entre experiências vivenciadas no passado, no presente e prospectar imaginativamente possibilidades de futuro. Importante salientar que as transformações não ocorrem de uma maneira ordenada, pois a criação de horizontes de futuro (Araújo \& Lopes de Oliveira, no prelo) altera a compreensão do sujeito sobre si, no presente, permitindo reconstruir o passado, algo que os estudos recentes sobre subjetividade e memória (Wagoner \& Brescó, 2016) igualmente evidenciam.

A trajetória biográfica de uma pessoa lida com um duplo processo. Envolve, por um lado, a ideia de um si mesmo que é significado pelo sujeito como permanecendo ao longo do tempo, e por outro, as dinâmicas de descontinuidade e mudanças no curso de vida (Freire \& Branco, 2016). Esta noção de trajetórias é incorporada no presente trabalho como a unidade de análise dos processos de desenvolvimento humano.

Zittoun (2009) salienta que uma trajetória biográfica é constituída por experiências disruptivas e de continuidade, as primeiras causadoras de transições de desenvolvimento. Transições são a resposta psicológica, subjetivamente relevante ou possível face às circunstâncias da vida, sejam elas eventos biológicos (como a puberdade), institucionais (acadêmica ou profissional), ou qualquer situação imprevista que gere uma ruptura significativa e particular, no indivíduo. Para a autora (Zittoun, 2009, p.05), "[a]s rupturas sinalizam o fim de um modo de ajuste, diante do qual novas dinâmicas devem ser estabelecidas". São um chamado do sistema de self para novas ideias, novas soluções e novas formas de pensar, que surgem como efeito proximal ou tardio de uma ruptura. Portanto, a transição demarca a construção de um novo modus operandi pelo sistema de self, que representa uma nova forma de agir, pensar e organizar seu modo de viver. Para tanto, os sujeitos se utilizam de dispositivos imaginários e discursivos diversos, que os ajudam a sustentar o projeto de continuidade de si como SSD, no tempo irreversível (Araújo \& Lopes de Oliveira, no prelo). 


\section{Violência, pobreza e exclusão social no Brasil: a produção social da delinquência juvenil}

O passado colonialista, baseado na exploração, escravidão, desigualdade e destruição das culturas nativas e, posteriormente, a dependência imperialista dos países do Norte, é parte da formação histórico-social da América Latina, que se faz presente tanto entre países de colonização espanhola como portuguesa em nosso continente. Notam-se ainda hoje muitos indicadores de que as marcas do passado violento foram aqui deixadas como uma herança cultural dos colonizadores, delineando condições de existência e sendo incorporadas ao sistema de valores e crenças, que norteiam as relações sociais e nossa própria identidade como sujeitos (Adelman, 1999). Os efeitos produzidos por elas expressam-se quer na forma da violência explícita (prevalência do crime organizado e do tráfico de drogas; elevadas taxas de corrupção; desapropriação da coisa pública na forma de grilagem de terras, destruição do meio ambiente; exploração de trabalhadores em condição de escravidão, xenofobia, homofobia e preconceitos), quer implicitamente relacionados à naturalização de características culturais enraizadas no funcionamento cotidiano da sociedade e do estado, tais como a reprodução de uma estrutura estatal cara, burocrática e ineficaz, descomprometida com as necessidades e direitos dos cidadãos, que são expostos a situações de insegurança, risco e vulnerabilidade social, diante de formas de urbanização descontroladas e hostis (Laurie \& Shaw, 2018). O fato é que, na maioria dos países da América Latina, a intensidade da violência é muito maior do que em países avançados (Salama, 2014), e mesmo do que em outros com PIB e problemas econômicos semelhantes.

A violência é um fenômeno complexo e multideterminado, que se refere aos fatores que causam uma diferença entre o potencial e a realidade, no mundo (Galtung, 1969, 1990). Desse modo, a fim de se compreender a gênese e os impactos sociais e subjetivos da violência, precisa-se de um olhar plural e sistêmico, historicamente circunstanciado. Minayo (2006) argumenta que, embora a violência se expresse por meio de ações individuais e/ou de grupos, não se deve considerar que esta possua raízes biológicas, nem interpretá-la como parte da natureza ou da psicologia humana. Na verdade, conforme Pedersen (2009, p. 112), trata-se de um fenômeno situado "no cruzamento do social, do político, do econômico e do cultural, do qual ela exprime correntemente as transformações e a eventual desestruturação". No caso das sociedades contemporâneas, adicionalmente, a compreensão da construção social, dos significados e efeitos contemporâneos da violência, em suas múltiplas formas de expressão, exige levar em consideração as mudanças liberais, que tornaram o capital econômico o principal eixo organizador do sistema social. Em relação às relações humanas, o liberalismo econômico e o capitalismo radical têm promovido uma preocupante decomposição de valores, sobretudo os que se referem às questões comunitárias e de interesse coletivo, dando lugar a um crescente individualismo e à competição acirrada, com significativos efeitos intersubjetivos e individuais (Branco, Manzini \& Palmieri, 2012).

Tomando a fase mais recente dessa história, para não estender o debate, a unificação econômica do mundo em torno do modelo econômico capitalista, que decorreu do fim da União Soviética, em 1989, substituiu o temor da Guerra Fria, expressão de uma oposição dicotômica, por novos temores e tensões socioeconômicas e políticas multilaterais, em meio às quais vários países lutavam por um mesmo objetivo, o de alcançar a riqueza e a hegemonia econômica. Neste cenário, o Brasil está em posição peculiar. Em termos macroeconômicos, este se caracteriza como uma nação rica, que ocupou em 2018 a 9a posição mundial (FMI, 2017). Ao mesmo tempo, como resultado de uma distribuição da riqueza concentradora e injusta, paradoxalmente, o país ocupa a $9^{\mathrm{a}}$ posição em 
desigualdade de renda (pnud, 2018) e a liderança em concentração de riqueza nas mãos do $1 \%$ mais rico da população (CEPAL, 2018).

Em suma, a violência estrutural, a concentração de renda e a cultura do consumo configuram elementos centrais para uma compreensão mais aprofundada da juventude e do fenômeno da delinquência juvenil, na contemporaneidade.

\section{Juventude, delinquência juvenil e atendimento socioeducativo}

Juventude não se refere a grupo etário, mas a uma condição social (Pais, 1990), forjada em meio a práticas sociais cotidianas, cercadas de valores contraditórios e ambíguos. Tais práticas resultam de canalizações socioculturais e pessoais variadas que, no ocidente compartilham entre si uma orientação semiótica comum, a desvalorização das gerações mais novas (vistas como impulsivas, irresponsáveis, improdutivas, inúteis) e a reificação da vida adulta (ajustada, produtiva, responsável e equilibrada).

A construção social da condição juvenil ganhou visibilidade no século XIX (Cole \& Cole, 1994). Os efeitos sociológicos da Revolução Industrial conferiram às escolas um novo lugar como modelo de socialização e transmissão cultural-científica das novas gerações, que passaram a ter importância crescente na organização da sociedade. $\mathrm{O}$ modo de produção fabril passou a exigir cada vez mais formação e especialização do trabalhador, a qual se podia obter por meio da educação escolar (Ariès, 1978). As crianças não mais passavam da infância à condição trabalhadora. Esta foi adiada por alguns anos, e surgiu aí a adolescência e a juventude, como fase intermediária entre a infância e a vida adulta. Ao mesmo tempo, o fortalecimento das escolas ia ao encontro do projeto de sociedade visado pelos novos capitalistas e reformadores cristãos, que reificavam o trabalho, a ocupação e condenavam o ócio.

Com o advento da Psicologia moderna, os valores sociais sobre a juventude - pautados na regulação moral e sexual da conduta - encontraram justificativas científicas, que levaram a teorias prescritivas e normalizantes (cf. Lopes de Oliveira, 2006). Contrariamente, as abordagens contemporâneas do desenvolvimento humano, entre elas os enfoques críticos apoiados pela Psicologia cultural, enxergam no jovem sujeito ativo e participativo, que pode ter importante papel na vida social e comunitária. Entende-se que cada contexto sociocultural dispõe de uma pauta não homogênea de representações e expectativas sobre os jovens que tanto ajudam a definir sua conduta, como podem ser objeto de resistência por eles. Ao mesmo tempo, mudanças de status social na família, escola e grupos, e distintas experiências socioafetivas próprias da juventude contribuem para reposicionar o jovem em relação aos requerimentos do espaço social, possibilitando a emergência de novos sistemas de sentidos. Em outras palavras, a formação individual na juventude resulta de uma composição ativa entre as expectativas originárias da sociocultura e as intencionalidades subjetivas de cada jovem.

No Brasil, a desigualdade socioeconômica e o descompromisso do Estado com as novas gerações dificultam sobremaneira as condições equânimes de desenvolvimento, ao impedirem segmentos em desvantagem social de receber adequada formação educacional e profissional. Esse canário dá origem a juventudes desiguais, não apenas diversas. $\mathrm{Na}$ atualidade, de modo particular, a relação entre juventude, escola e sociedade se tornou um tema desafiador, tendo como efeitos a permanência de um número significativo deles fora da escola, excluídos do sistema produtivo. Pode-se, assim, perceber uma íntima interdependência entre as formas explícitas e implícitas, visíveis e invisíveis, de violência de que os jovens são vítimas, no âmbito macropolítico, o fenômeno da infração juvenil e as contradições do atendimento socioeducativo (Paiva, Lopes de Oliveira, Colaço, 2019).

No Brasil, a resposta contemporânea do Estado em face da infração juvenil está regulada pela 
Constituição Federal de 1988 e pelas leis de proteção que se seguiram a ela, considerando o contexto da juventude e do atendimento socioeducativo aos autores de ato infracional. Por serem penalmente inimputáveis até a idade de 18 anos incompletos, frente ao cometimento de ato análogo a uma contravenção penal cometida por adulto, estão sujeitos a um sistema especial de responsabilidade. Ao ato infracional praticado por criança (até 12 anos incompletos) corresponderão medidas de proteção, enquanto que ao adolescente (entre 12 e 18 anos incompletos) a quem se atribua autoria em ato infracional, aplicam-se as medidas socioeducativas previstas no artigo 112 do ECA.

Se por um lado, a medida socioeducativa representa uma sanção por um ato gravoso de violação do contrato social, que impõe restrições ao direito individual do adolescente (como a liberdade de ir e vir), por outro, a medida não pode se eximir do dever de atender aos direitos fundamentais desse mesmo adolescente, como sujeito em desenvolvimento, definidos pela Constituição Federal do Brasil. Ou seja, o cumprimento da medida socioeducativa não deve subtrair do adolescente as alternativas de expressão e linguagem não adstritas à infração, mas auxiliá-lo a assumir o papel de agente de suas próprias escolhas, com possibilidade de posicionar-se diante das condições profundamente adversas nas quais a sua subjetividade, com frequência, se constrói (Machado, 2018).

As medidas socioeducativas previstas por lei vão desde a advertência e a obrigação de reparar o dano, às quais são de cumprimento imediato; passando pela liberdade assistida; até as medidas mais gravosas, restritivas de liberdade, às quais são cumpridas em regime de semiliberdade ou de internação em estabelecimento educacional. Todas elas são aplicadas por determinação judicial, no marco do sistema de justiça juvenil.

No Distrito Federal, que é a delimitação geográfica e espacial dos estudos de caso que serão apresentados a continuação, o sistema socioeducativo sofreu grande expansão na última década, tendo ampliado a rede de unidades de internação estrita, com vistas a enfrentar os problemas de superlotação, insalubridade, e violação de direitos humanos de crianças e adolescentes anteriormente verificados na única unidade existente até então. $\mathrm{Na}$ nova configuração, foi criada uma unidade destinada a acolher adolescentes e jovens em processo de desligamento do sistema socioeducativo, denominada Unidade de Saída Sistemática (UNISS). A proposta é que os adolescentes possam ser inseridos em atividades externas à instituição, passando a ter mais convívio com a família de origem e usufruindo de oportunidades de vivenciar experiências laborais e educacionais específicas, que promovam habilidades necessárias à vida cidadã em liberdade, no contexto social de sua comunidade e no mercado de trabalho. Em outras palavras, a unidade de internação de saída sistemática operaria como um campo intermediário de vivências, entre a internação estrita e diferentes esferas de experiência cotidiana do jovem, como o domicílio da família e o trabalho. Coerente com esta perspectiva, à medida que estes contextos voltam a fazer parte do cotidiano do adolescente estes passam a gozar de crescente importância, embora este seja um processo sempre canalizado pelas possibilidades e limites próprias de cada campo sociocultural, interdependentes do nível de escolaridade pregressa e das oportunidades de qualificação profissional e de inserção no mercado de trabalho (Machado, 2018).

A existência de uma unidade de internação com estas características expõe um quadro complexo sobre o cenário da socioeducação no DF, que os resultados empíricos apresentados adiante ajudarão a elucidar. Considera-se a unidade de saída sistemática do DF um contexto de desenvolvimento juvenil bastante peculiar, pelo modo como exerce o papel catalisador de trajetórias de desenvolvimento. Por um lado, a transferência do jovem para esta nova esfera de experiência, onde há mais liberdade de ir e vir, sinaliza para ele que a medida socioeducativa em breve será concluída- o 
que pode ser mobilizador de rupturas e transições significativas. Por outro lado, sendo ela regulada pelas normas próprias das unidades de internação, preserva muitas das características opressoras de uma instituição total (Goffman, 2004/1981). Desse modo, percebe-se que ela traduz e reproduz valores socioculturais da sociedade brasileira e latino-americana e, ao mesmo tempo, reifica contradições e valores próprios da cultura socioeducativa, comunicando ao jovem que ele está pretensamente em uma nova etapa da internação, e em outro contexto institucional, estando ao mesmo tempo na fronteira entre duas condições subjetivas antagônicas, prisão e liberdade. Estamos diante de um contexto de desenvolvimento humano para o qual a psicologia semiótico-cultural se mostra útil e sua arquitetura conceitual pode contribuir com explicações produtivas.

\section{Método}

Com vistas a investigar a produção de trajetórias de desenvolvimento na fronteira física e simbólica entre o 'dentro' e o 'fora' da medida socioeducativa de internação, a unidade de saída sistemática constituiu-se no locus privilegiado da investigação. A análise das práticas sociais cotidianas e interações que se dão nessa esfera de experiência é importante para que se compreendam os significados por meio dos quais a cultura socioeducativa canaliza o desenvolvimento dos jovens participantes da pesquisa (Rossetti-Ferreira, Amorim, \& Silva, 2000; Machado, 2018), potencializando ou bloqueando rupturas e reorientações de trajetórias. Isto porque os sentidos construídos pelos adolescentes e jovens em cumprimento de medida não podem ser pensados fora das condições materiais de existência desses indivíduos nas suas relações com a sociedade, quer pela presença, quer pela falta de condições colocadas a seu dispor. Por esta razão, todas as dimensões, físicas e simbólicas, relacionadas a esta esfera de experiência do adolescente, antes e depois do encerramento da medida, são do interesse da pesquisa (Mattos, 2013; Sposito, 2005).

As informações de pesquisa foram construídas em, pelo menos, dois momentos. O primeiro se deu no interior da unidade de internação, durante a internação na UNISS, e o segundo, quatro meses após o encerramento da medida, em local(is) acordados com cada participante. O lapso temporal médio de seis meses entre uma entrevista e outra, dentro dos nove meses de acompanhamento, foi estabelecido pelo entendimento de que a internalização das novidades relacionadas à nova condição de liberdade vivida pelo participante requer tempo até que possam ser narradas.

A psicologia cultural contemporânea tem construído um sólido edifício teórico, mas não tem conseguido ainda consolidar sua própria metodologia de análise, apesar dos avanços dos últimos anos (Salvatore, 2014). No sentido de construir uma metodologia para a presente pesquisa que fosse coerente com os pressupostos apresentados no referencial teórico, adotou-se em seu desenho metodológico uma combinação de distintas técnicas e procedimentos, dentre os quais o presente trabalho se dedica a focalizar o Radar de Relações Interpessoais (RRI), sem desconsiderar informações relevantes geradas por outros métodos para a compreensão do fenômeno pesquisado. Foram eles: (a) imersão etnográfica na unidade de internação investigada; (b) leitura de prontuários dos internos; (c) a construção de fichas sociodemográficas com informações sobre os jovens selecionados para o estudo; (d) acompanhamento dos jovens e equipe de referência em atendimentos e intervenções diversas; (e) interações informais, inclusive por telefone; (f) realização das entrevistas, propriamente ditas. Nestas últimas, foram utilizados dois instrumentos, visando oferecer aos participantes dispositivos dialógicos para a produção de narrativas: o Radar de Relações Interpessoais (RRI) e o Jogo "Trilha da Vida". O primeiro foi adaptado do trabalho de Pereira (2009) e Yokoy de Souza (2007), enquanto o segundo foi desenvolvido pela segunda autora. 
O instrumento Radar de Relações InterpessoaisRRI (Machado, 2018; Yokoy de Souza, 2011) está representado nas figuras 1,2 e 3 . Foi desenvolvido a fim de possibilitar materializar em representação gráfica o sentido atribuído por um sujeito si mesmo em relação às alteridades e redes sociais significativas relacionadas a esferas de experiências particulares, em dado momento. Conforme as figuras, parte-se de um quadrado dividido em quatro quadrantes e preenchido por círculos concêntricos, nos quais o respondente insere marcas que definem quem são e que importância têm as alteridades reconhecidas por ele. O centro da figura representa o próprio sujeito. O preenchimento do quadro é seguido de uma entrevista na qual ele narra as relações sociais que ele estabelece, em diferentes esferas de experiência.

No caso presente, foram selecionadas: (1) a unidade de internação; (2) a comunidade; (3) a família; e (4) o trabalho. No início de cada seção de entrevista individual, realizada nos três tempos da pesquisa (T1, T2 e T3), os jovens participantes eram orientados a posicionarem no quadro, que tinha seu próprio nome no centro, as alteridades significativas relacionadas a cada uma das quatro esferas de experiência identificadas em cada quadrante. Cada pessoa era representada por um adesivo colorido e a posição, mais próxima ou distante do centro, revelava a intimidade, significância e apoio atribuído a ela pelo participante.
João, Cauã e Severino ${ }^{1}$ foram os três participantes do estudo que construíram dois ou mais RRI. Este fato possibilitou a visualização de mudanças nas dinâmicas relacionais ocorridas em meio às saídas sistemáticas e após o encerramento da medida socioeducativa de internação, e seu papel na mobilização afetiva do adolescente, diante das mudanças em curso, envolvendo situações de hierarquia, proximidade e distanciamento físico e emocional.

Apresentaremos e discutiremos os resultados a partir da RRI de cada um dos três e, em seguida discutiremos o potencial heurístico desta ferramenta para a compreensão do fenômeno da violência juvenil e da socioeducação pela psicologia cultural.

\section{Resultados}

Esta seção terá início com a apresentação das informações recolhidas nas entrevistas mediadas pelos RRIs, seguida por um apontamento dos seus aspectos mais singulares nos três tempos (T1, T2 e T3, conforme o caso), ${ }^{2}$ com enfoque idiográfico,

\footnotetext{
Nomes fictícios

O primeiro RRI (T1) foi completado quando todos estavam internos na unidade de saída sistemática. Cauã e Severino evadiram da unidade antes da expedição da sentença judicial de liberação e apenas Severino aceitou encontrar-se com a pesquisadora durante a evasão, para T2, e novamente ao ser apreendido para concluir a medida, em T3; João foi formalmente liberado por sentença, mas acabou preso em seguida, por uma suspeita que se mostrou infundada, mas
}

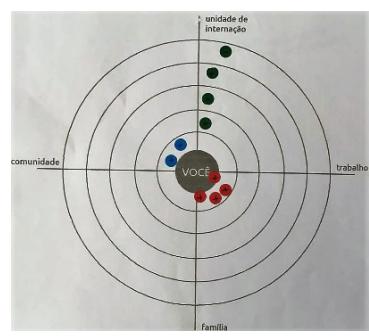

T1

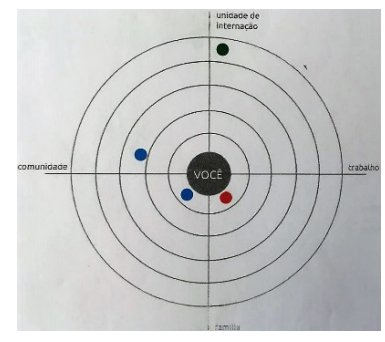

$\mathrm{T} 2$

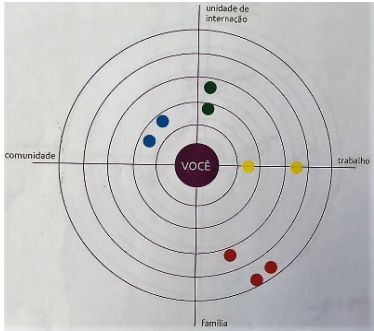

T3

Figura 1. RRIs de Severino

Fonte: Material construído pelo participante. 


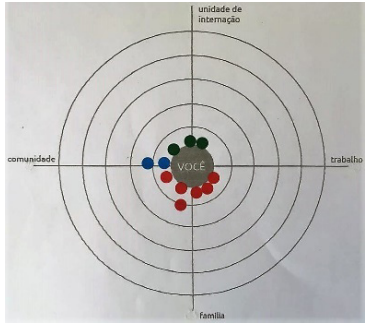

T1

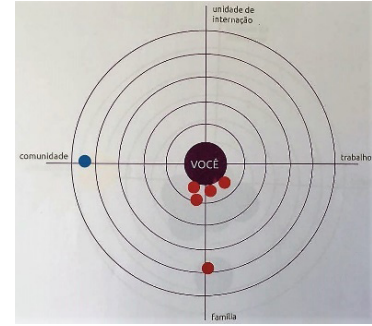

$\mathrm{T} 3$

Figura 2. RRIs de João

Fonte: Material construído pelo participante.

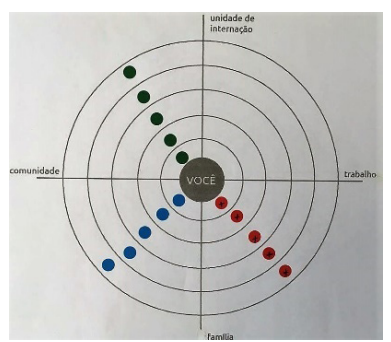

$\mathrm{T} 1$

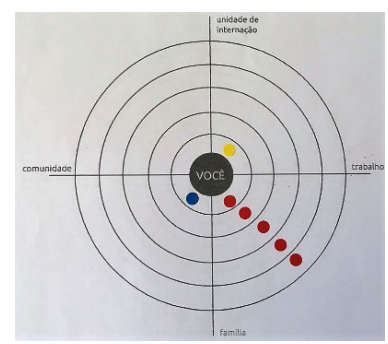

T3

Figura 3. RRIs de Cauã

Fonte: Material construído pelo participante.

Tabela 1.

Resultado quantitativo dos Radares de Relações Interpessoais

\begin{tabular}{lcccccccc}
\hline \multirow{2}{*}{ RADAR DAS RELAÇÕES INTERPESSOAIS } & \multicolumn{3}{c}{ Severino } & \multicolumn{3}{c}{ João } & \multicolumn{2}{c}{ Cauã } \\
\cline { 2 - 8 } & $\mathrm{T} 1$ & $\mathrm{~T} 2$ & $\mathrm{~T} 3$ & $\mathrm{~T} 1$ & $\mathrm{~T} 3$ & $\mathrm{~T} 1$ & $\mathrm{~T} 3$ \\
\hline Família & 4 & 3 & 3 & 6 & 5 & 5 & 5 \\
\hline Trabalho & 0 & 0 & 2 & 0 & 0 & 0 & 1 \\
\hline Socioeducação & 4 & 1 & 2 & 3 & 0 & 5 & 0 \\
\hline Comunidade & 2 & 2 & 2 & 2 & 1 & 5 & 1 \\
\hline Total & 10 & 6 & 9 & 11 & 6 & 15 & 7
\end{tabular}

Fonte: Elaboração da pesquisadora.

e terminando com o estabelecimento de algumas comparações e aproximações entre os três casos.

As condições em que se deram (ou deixaram de ocorrer) as entrevistas sugerem já um indicador de análise sobre as trajetórias de vida mediadas pelo

que impediu o encontro em T2; a entrevista com Cauã em T3 acontece no Centro de Prisão Provisória do Sistema Penitenciário. A entrevista com João em T3 foi realizada após a sua liberação da detenção provisória, em seu apartamento, onde vive com a esposa e a filha atendimento socioeducativo, quando se verifica que os três participantes passaram por algum tipo de agravo em meio ao processo de desligamento da medida socioeducativa, seja por evasão (Cauã e Severino), ou por prisão injustificada (João).

Na tabela 1 está plasmado o número de pessoas significativas que cada jovem apontou nos diferentes momentos da pesquisa. Os resultados quantitativos são relatados em uma análise individualizada, as quais serão apresentadas a seguir. 


\section{Caso 1: Cauã}

Os pais de Cauã se separaram quando ele tinha 5 anos de idade e, após o divórcio, sua mãe se mudou com ele para a região Nordeste do Brasil. Cinco anos mais tarde, é trazido pela mãe de volta a Brasília para morar com uma tia paterna, a quem por vezes ele chama de mãe, percebida como seu principal suporte social. Quando a pesquisa se inicia (T1), ela havia retornado à unidade após a internação hospitalar para a retirada cirúrgica de um preservativo alojado em seu esôfago. Ele parecia deprimido, sentia medo de morrer por sua condição médica e por ameaças de gangue rival, tendo sido solicitado apoio psicológico para ele. Em uma saída de fim de semana, Cauã evade. Em T3 ele já se encontra preso no Sistema Penitenciário. A mãe biológica não convive com o jovem e não aparece em nenhum dos dois RRIs produzidos por ele, mas sim nas narrativas enquanto realizava a atividade, sempre envolta em uma alta carga emocional negativa. $\mathrm{O}$ tio (marido da tia), aparece em T1 mas não em T3. O ‘desaparecimento' do tio do RRI expressa a mágoa de Cauã pois o tio sugeriu à sua esposa denunciar Cauã à polícia após a evasão da UNISS, ao que a tia se recusou a fazer por entender que ele estava melhor psicologicamente após a evasão do que antes.

Cauã não tivera nenhuma experiência de trabalho até T3, quando, estando evadido, trabalhou com o pai como assistente de pedreiro. Em relação aos pares, Cauã demonstra muita desconfiança e inclui no RRI (apenas em T1 e distante dele) um adolescente da Unidade. Em função de rixas entre gangues rivais, presentes inclusive na unidade de internação, ele se diz jurado de morte. As outras quatro pessoas do ambiente socioeducativo por ele mencionadas são membros da equipe profissional da unidade: duas agentes, uma das quais o ajudou durante o período de hospitalização; o professor de educação física que lhe dá "altos conselhos"; e a técnica de referência. Em T3, essa esfera de experiência já não está presente: nenhuma das pessoas da esfera socioeducativa foram mencionadas como tendo papel significativo em sua vida. Os amigos e a ex-namorada que são citados em T1 já não estão presentes em T3. No segundo momento, apenas a vizinha é identificada entre os membros da comunidade com quem se relacionou enquanto esteve evadido.

\section{Caso 2: João}

João chegou à unidade de saída sistemática aos 19 anos, para passar 1 mês. Era a segunda vez que era transferido para lá e estava próxima sua saída compulsória após 3 anos de cumprimento da medida de internação. Foi introduzido na carreira infracional aos 13 anos, tendo sido apreendido por primeira vez aos 15 anos por receptação, período que coincide com o nascimento da filha. Sua mãe mora nos Estados Unidos e o jovem é acompanhado pelo pai e avó paterna. Tem uma filha de 3 anos com a namorada, com quem tem relacionamento estável. Logo após ser liberado da MSE, ele acaba sendo injustamente preso, acusado de ser o proprietário da droga encontrada no local em que se reunia com amigos, em uma operação policial. Por ter ficado inacessível durante os quase três meses que passou no sistema prisional, João apenas participou em T1 e T3.

As mudanças em T3, comparadas com T1, são: (a) a inclusão da esposa no RRI, posicionada desta vez no primeiro plano, junto com a mãe e a filha; (b) o distanciamento da avó, posicionada agora em segundo plano; (c) o deslocamento do pai, que sai do plano mais próximo para o $4^{\circ}$ nível de proximidade, demonstrando um distanciamento, mesmo que outros momentos da entrevista revelem que o pai parece estar bastante presente na vida de João agora, após a sua liberação do Centro de Detenção Provisória.

Sobre a companheira, em T1 ela parece suscitar nele afetos hostis, que menciona o desejo de jamais tê-la conhecido. No episódio da prisão, contudo, ela se posiciona proativamente em sua 
defesa e luta para reunir provas que o livrassem da detenção. Tal atitude parece ter promovido uma guinada nos afetos do participante e na percepção dele sobre o status da companheira na sua rede de relações sociais. João também passa a expressar um novo senso de si, com a emergência de novos posicionamentos, tais como "pai de família" e "jovem trabalhador". Estes posicionamentos colocam-se em tensão com a velha posição dominante "eu como adolescente infrator", e busca levá-la para a periferia de seu sistema de self. Ao lidar com significações complexas, Branco e Valsiner (2010) propõe que o sistema de self pode se reconfigurar, em função das relações sociais específicas do indivíduo, e dos contextos culturais dos quais ele participa.

O jovem tinha uma boa convivência com pares dentro da unidade de internação. Em T1, ele cita três dos companheiros mais próximos, mas enfatiza ter bom relacionamento com vários deles. Em T3, todas essas relações foram desfeitas, e João já não mantém contato com eles. Na esfera da comunidade, João menciona dois amigos em T1, ambos envolvidos em atos infracionais. Em T3, essas pessoas deixam de estar representadas no RRI. "Todos eles estão bem distantes [...]", diz. “[...] os amigos que eu tinha tão tudo preso. Uns que estava comigo era de menor hoje já estão maior. Uns já pegou nove anos e tantos mês (de condenação), outros já estão perto de pegar cadeia maior. Outros já tem cadeia, e já tão pegando mais [...]”. A esfera do trabalho inexiste para João em T1 e T3. No entanto, nota-se entre os dois momentos da pesquisa uma intensa reconfiguração sistema de self de João e respectivos campos afetivo-semióticos, acompanhados da emergência de novas perspectivas de futuro. Por exemplo, em T1, quando questionado sobre alternativas de vida após a liberação da medida, ele expressa que não vê para si uma vida fora da criminalidade. Menciona que seu único trabalho foi o 'ofício da vida bandida', que ele aprendeu aos 13 anos. Já em T3, diante dos novos posicionamentos em gênese, a esfera de experiência 'mundo do trabalho'é incluída, sendo retratada como uma conquista almejada para o ano seguinte (2018), ainda que João evidencie uma percepção realística dos desafios envolvidos: "Apesar de nunca ter trabalhado, eu sou aquele cara que tenho disposição para fazer o que me mandar".

\section{Caso 3: Severino}

Severino foi apreendido pela primeira vez por roubo, aos 16 anos. Ele havia deixado a casa da família, onde morava com a mãe e o irmão, indo viver com amigos. A internação estrita veio após três passagens pela internação provisória. Com 19 anos, momento da pesquisa, Severino estava no $8^{\circ}$ ano do ensino fundamental e aguardava iminente liberação pelo juiz, mas evade da instituição, voltando a ser apreendido meses depois. Foi o único participante com o qual se realizou todas as fases de entrevista previstas.

A família representada por Severino no RRI inclui a mãe, a avó e o irmão, que estão presentes nos três momentos (T1, T2 e T3), mas representados diferentemente quanto à proximidade de si: em $\mathrm{T} 1$ e T2 eles aparecem no nível mais próximo, ao que Severino esclarece ter sido apenas um distanciamento físico, pelo fato da mãe ter se mudado a outra região administrativa do DF após a sua separação do marido. Este, padrasto de Severino, aparece em T1 como da esfera familiar, não é citado em T2, mas volta a aparecer em T3, dessa vez inserido na esfera do trabalho. Em T1 e T2, o mundo do trabalho inexiste para Severino. Apenas em T3 ele passa a relatar duas experiências de trabalho informal ocorridas enquanto esteve evadido, que foram muito significativas para ele. $\mathrm{O}$ ex-padrasto, que sempre o apoiou, o levava ao trabalho como assistente de gesseiro após a evasão; além disso, nesse mesmo período, um senhor da comunidade começou a ensiná-lo a reformar estofamento e, com isto, pôde obter algum dinheiro para seu sustento. Enquanto estava na Unidade de Saída Sistemática, Severino reporta uma sociabilidade relativamente 
plural. O colega de quarto é o único que aparece nos três tempos, mesmo quando sua rede se mostrou empobrecida, em especial, após a evasão. Além dele, as outras três pessoas mencionadas em T1 são do mundo adulto, sendo a técnica da unidade relatada como uma pessoa de referência. Dois agentes também são reportados, sendo um como referência positiva, que lhe dá "altos conselhos", e o outro, como desafeto. Em T3, a pesquisadora passa a aparecer no RRI como parte desse mundo adulto que ele conheceu na socioeducação, com quem manteve contato positivo, ao longo daquele período. As duas pessoas da comunidade por ele citadas, em T1, são os amigos com quem Severino costumava cometer infrações, sendo que um deles deixa de ser mencionado a partir de T2. Em T3 a esfera comunitária muda sua configuração, passando a constar dela duas pessoas que exerceram influência positiva na vida de Severino enquanto ele esteve evadido, tendo sido decisivas para que ele pudesse vislumbrar novas possibilidades de futuro. Uma delas era o 'tiozinho da padaria', "uma das pessoas que estavam lhe dando uma força: 'Levava altas ideias comigo também, dava uns conselhos, uma ideia positiva, queria saber como é que eu tava, [saber se] eu tava de boa"'. A segunda pessoa citada é um antigo conhecido que, diferentemente de outras experiências, o introduz a um novo ambiente e círculo de relacionamentos, constituído de pessoas que não tinham envolvimento infracional.

Alguns trabalham, outros são sustentados pelos pais... não é um círculo do tipo daquele lá do crime, tá ligado? Com os pensamentos assim de fazer o corre. Lá os caras era tranquilo. Pensava mais positivo, essas coisas. Eu vi a diferença. Completamente diferente das pessoas que eu conhecia

Severino atribui a cada pessoa incluída nos RRIs a carga emocional correspondente, quer de hostilidade e distanciamento, quer de afeição e proximidade. Em decorrência de uma relação de hostilidade com um servidor da unidade, mencionado em T1, Severino decide evadir. A sua percepção era que o agente influenciaria negativamente no conteúdo do relatório e ele terminaria voltando para a unidade de internação, em vez de obter a liberdade. Esta percepção torna-se definidora de uma mudança no curso da trajetória de Severino. Entre as alternativas de futuro, seja como jovem livre, jovem infrator em cumprimento de medida por prazo indeterminado, e jovem evadido, ele se deixa afetar pelas provocações do servidor e opta pela terceira alternativa.

A análise dos instrumentos revela mudanças importantes na sua rede social e de apoio entre T1 e T2. Sobre pessoas mencionadas alguns meses antes, Severino comenta que "alguns tá perto, outros já afastou um pouco. Dois adolescentes são citados em T1, um dos quais foi apresentado como alguém que o ajudaria 'em qualquer tipo de situação [...]”, mas já não estão disponíveis para ele em T2. O RRI, em T2, expressa bem a tomada de consciência pelo jovem da falta de suporte social com que ele pode contar, agravada pela condição de estar evadido da instituição. Mas, Severino demonstra uma consciência crítica da situação, que lhe permite refletir sobre os novos possíveis cenários de maneira prática. Diante de sentimentos ambivalentes, em T2 ele tem uma mudança de percepção de si e começa a cogitar a possibilidade de retornar à unidade de internação para finalizar o cumprimento da medida, a fim de poder sair de lá 'pela porta da frente', e com chances de construir uma nova trajetória.

Este novo campo de possibilidades parece ter relação com algumas experiências como trabalhador, vivenciadas por Severino no período em que esteve evadido, que atuou informalmente como assistente de gesseiro do padrasto, como aprendiz de estofador com um vizinho e na montagem e instalação de equipamentos de som em eventos, ajudando um amigo. Severino, que disse ter optado por não retornar à vida infracional, também começa, em T2, a vivenciar experiências diferentes das que marcaram sua adolescência. Ele é inerido por 
um amigo em outros círculos de amizades, que o aproximam de "uns lugares diferentes, preparando umas coisas diferentes que eu não tinha em mente de fazer $[\ldots]$ com umas pessoas diferentes, com outros pensamentos... um bocado de coisa que nem passava na minha mente". Ele se refere a atividades de campo como trilhas e acampamentos. A partir da consideração dos relatos de entrevista acerca dessas experiências, ganha outro sentido a reconstituição da rede de relacionamentos interpessoais de Severino em T3. Ele projeta ainda, para o término do cumprimento da medida socioeducativa, voltar a ter a família bem próxima a ele.

\section{Discussão}

Os estudos de caso aqui apresentados expressam o valor heurístico do instrumento Radar de Relações Interpessoais (RRI), na análise longitudinal de dinâmicas de desenvolvimento e delineamento de trajetórias juvenis. Desde uma perspectiva idiográfica, a análise dos registros dos participantes nos RRIs analisadas lança luz sobre os efeitos subjetivos das vivências juvenis no contexto da socioeducação. Ao verificar a diminuição das alteridades que são reconhecidas como parte da rede social dos jovens participantes e o enfraquecimento dos vínculos com as alteridades vistas originalmente como significativas, fica claro que a passagem pelo atendimento socioeducativo deixa marcas profundas em suas trajetórias de vida e compromete um princípio básico do desenvolvimento humano, as relações interpessoais.

Em primeiro lugar, as práticas no contexto socioeducativo refletem um sistema de valores e crenças sociais sobre a juventude, amplamente disseminados e reproduzidos na forma de práticas, discursos, escalas de hierarquia e jogos de expectativas que recaem sobre ela. Nos casos analisados, identificamos como exemplo, usar o poder de ameaça de um grupo juvenil sobre outro (Cauã), ou o servidor que testou a capacidade de resistência de Severino. A falta de suporte e proteção do sis- tema socioeducativo, em ambos os casos, levou os jovens à evasão. Nessa medida, os estudos apontam que a socioeducação, muitas vezes, deixa de promover a chamada 'ressocialização' dos jovens, despreparando-os para a participação social e contribuindo para afastá-los das redes significativas previamente existentes.

Os RRI possibilitaram uma visualização gráfica dos impactos subjetivos e sociais da experiência de saída sistemática, que se caracteriza para os participantes como um espaço de confluência entre diferentes esferas, ao favorecer o convívio familiar, experiências comunitárias diversas e a aproximação ao mundo do trabalho, mas nem por isso deixa de criar barreiras à autonomia e ao desenvolvimento dos jovens atendidos. A ferramenta, na realidade muito simples, permitiu identificar como, progressivamente, algumas dessas esferas, e as alteridades a elas relacionadas, vão perdendo a sua preponderância, enquanto outras vão emergindo como fonte de forças semióticas importantes.

Nossa percepção, a partir dos resultados do estudo é que, por mais empobrecedora e tímida em termos de promoção de desenvolvimento que possa ser tal experiência, há margem para que estratégias variadas sejam adotadas pelos jovens para preservar um certo grau de saúde mental e controle sobre suas vidas. Nas condições aparentemente mais adversas, em que o percurso para liberdade parece oferecer oportunidades mais exíguas que a provação de liberdade, os jovens estudados parecem resistir. $\mathrm{O}$ apoio recebido de diferentes atores institucionais foi percebido como promovendo uma capa de proteção, que deixa de existir quando são liberados, tornando-os, portanto, em alguns casos mais vulneráveis. Sobretudo, a existência de Outros significativos, que se ofereçam como objetos de identificação, possíveis catalisadores de trajetórias saudáveis e de outras alternativas de desenvolvimento futuro, estejam eles dentro e fora da internação, foi percebido como aspecto importante para o alcance de condições que sustentem trajetórias de desenvolvimento desvinculadas da infração. 
Por fim, ainda que não tenhamos a pretensão de propor generalizações, em especial por se tratar de uma pesquisa qualitativa de corte idiográfico, é possível identificar entre os três casos, alguns pontos de aproximação quanto ao desenho das respectivas trajetórias. Os resultados revelaram que, mesmo seguindo percursos muito diferentes entre si após a saída, os RRIs apontam certa regularidade em termos da percepção dos jovens de empobrecimento das suas redes de apoio após a finalização da medida e seu retorno à comunidade. Assim mesmo, a família se mostrou a principal esfera de experiência na vida do jovem e, ao mesmo tempo, a mais estável, ou seja, aquela que preserva sua presença ao longo da vida do jovem, mesmo com ausências e mágoas persistentes, que afetam os vínculos familiares de alguns. Fica evidente na análise dos dados dos três casos que estes saem após três anos de medida socioeducativa, incluindo-se o período de saídas sistemáticas, dotados de experiências praticamente nulas relacionadas ao mundo do trabalho, em especial do trabalho aprendiz, preâmbulo para alternativas de trabalho formal. Após seu desligamento, essa situação tende a se agravar, já que o jovem deixa de contar também com o suporte institucional. Nesse sentido, a sociabilidade estabelecida no contexto da socioeducação pode ter importância similar à da família, ao menos quando o jovem encontra nesse contexto alteridades significativas e forma vínculos afetivos relativamente estáveis, o que se mostra fator de saúde mental enquanto se está imerso naquela esfera de experiência de uma forma quase totalizadora.

Esse aspecto autoriza para que se problematize a ideia de que a medida socioeducativa é um contexto de não-socialização e que a oportunidade de "ressocialização" ocorre no retorno do jovem ao convívio em sociedade; nem a medida socioeducativa é ausência de vida social, nem a saída dela garante modos saudáveis de vida social e comunitária. Verificamos que a sociabilidade relacionada à esfera da socioeducação, naturalmente, deixa de acontecer após a liberação do jovem, entretanto ela não é substituída por novos vínculos, na comunidade. Finalmente, é importante destacar que a esfera comunitária foi aquela que se mostrou mais instável e teve maior variação entre os casos. Fortalecer redes comunitárias não trata apenas de manter ou ampliar o número de pessoas envolvidas, mas da progressiva substituição dos relacionamentos que vinculam o jovem às práticas delitivas por novos relacionamentos e esferas de experiência, potencialmente mais saudáveis e produtivas, o que aconteceu com Severino. Esta conquista é central, se o objetivo é proporcionar novas trajetórias, que se constituam fora do modelo infracional.

A transição institucional do adolescente para a UNISS deveria demarcar a culminância do atingimento dos objetivos subjetivos e sociais da socioeducação, mas não é isso que se observa na prática. Em geral, a transferência dos adolescentes de uma unidade de internação estrita à de saída sistemática parece ter sido orientada por dois critérios principais: a proximidade do tempo previsto em lei para a saída compulsória, aos três anos de cumprimento da medida; ou pela mera inexistência de ocorrências disciplinares durante um período prolongado de internação. Percebe-se, portanto, que as trajetórias na socioeducação são atravessadas por dificuldades subjetivas institucionais, políticas e comunitárias, que terminam por desviar-se dos seus objetivos centrais, que visam romper com a trajetória infracional e construir vias alternativas de desenvolvimento.

Assim mesmo, a autorização para que o adolescente possa entrar e sair da UNISS a fim de realizar atividades externas de educação e trabalho teria por objetivo possibilitar a ampliação e a diversificação das esferas de experiência do jovem. No entanto, esse trânsito diversificado não é de fato ofertado a todos os adolescentes por diversas razões, como a escassez de vagas de capacitação profissionalizante ou de inserção laboral, agravadas por uma defasagem na escolarização, falta de qualificação profissional, além da própria estigmatização e 
preconceito em relação ao egresso. Consequentemente, essa falta de oportunidade termina por tornar-se restritiva no sentido de ampliar e a diversificar as esferas de experiência do jovem.

\section{Referências}

Abbey, E., \& Diriwächter, R. (2008). Innovating genesis: Microgenesis and the constructive mind in action. Estudios de Psicología, 30(3), 373-376.

Adelman, J. (1999). Colonial legacies: the problem of persistence in Latin America History. New York: Routledge.

Araújo, C. M., \& Lopes de Oliveira, M. C. S. (no prelo). A semiotic approach to developmental transitions: A young woman's dedication to religious consecrated life. Em M. C. S. Lopes de Oliveira, A. U. Branco, S. F. C. Freire (Eds.). Psychology as a dialogical science: self ans culture mutual development.

Ariès, P. (1978). História Social da Criança e da Família. (D. Flaksman, Trad.). Rio de Janeiro: LTC.

Bertau, M.C., Gonçalves, M., \& Ragatt, P. (2013). Dialogic Formations: Investigations into the Origins and Development of the Dialogical Self. Charlotte, NC: Information Age Publishing Inc.

Branco, A. B., Freire, S. F., \& Roncancio-Moreno, M. (2018). Teacher's role in the dynamics between self and culture. In G. Marsico \& L. Tateo (eds.), Emergence of Self in Educational Contexts (pp. 107-125). Springer Nature: Switzerland.

Branco, A. U., Manzini, R., \& Palmieri. M. W. (2012). Em Branco, A. U., Lopes-de-Oliveira, M. C. S. (Orgs.). Diversidade e Cultura da Paz na Escola: contribuições da perspectiva socioecultural (pp. 95-124). Porto Alegre: Mediação.

Branco, A., \& Valsiner, J. (2010). Towards cultural psychology of affective processes: Semiotic regulation of dynamic fields. Estudios de Psicología, 31(3), 243-251. Doi: 10.1174/021093910793154411
Comissão Econômica para a América Latina e o Caribe (2018). Panorama Social da América Latina 2017. Santiago: CEPAL.

Cole, M., \& Cole, S. (1994). O desenvolvimento da criança e do adolescente. Porto Alegre: Artmed.

Daaleman, T. P., \& Elder Jr., G. H. (2007) Family medicine and the life course paradigm. Journal of the American Board of Family Medicine, 20(1), 85-92. Doi:10.3122/jabfm.2007.01.060012

Elder Jr., G. H. (1985) Life course dynamics: Trajectories and transitions, 1968-1980. New York: Cornell University Press.

Fundo Monetário Internacional. (2017). World Economic Outloook Database. World Economic and Financial Surveys.

Freire, S. F., \& Branco, A. (2016). The Dialogical Self Theory in Perspective. Psicologia: Teoria e Pesquisa, 32, 25-33. Doi: http://dx.doi. org/10.1590/0102-37722016012426025033

Galtung, J. (1969). Violence, peace, and peace research. Journal of Peace Research, 6, 167-191.

Galtung, J. (1990). Cultural violence. Journal of Peace Research, 27, 291-305.

Goffman, E. (2004/1981). Estigma: notas de uma identidade deteriorada ( $4^{\mathrm{a}}$ ed.). Rio de Janeiro: Guanabara.

Gotlib, I. H., \& Wheaton, B. (Eds.). (1997). Stress and adversity over the life course: Trajectories and turning points. New York: Cambridge University Press. Doi: http://dx.doi.org/10.1017/ CBO9780511527623

Hermans, H. J. M., Kempen, H. J. G., \& Van Loon, R. J. P. (1992). The dialogical self: Beyond individualism and rationalism. American Psychologist, 47(1), 23-33.

Laurie, E. W., \& Shaw, L. G. R., (2018). Violent conditions: the injustices of being. Political Geography, 65, 8-16.

Lopes de Oliveira, M. C. S. (2006). A narrative and dialogical approach to self-development of adolescents involved in criminal activities. Apresentado em Fouth International Conference on the Dialogical Self, Braga. 
Lopes de Oliveira, M. S., \& Guimarães, D. S. (2016). Dossiê: Psicologia dialógica. Psicologia USP, 27, 165-167. Doi: http://dx.doi. org/10.1590/0103-6564D20162702http://dx. doi.org/10.1590/0103-6564D20162702

Machado, K. R. (2018). Produção de subjetividades na fronteira entre o dentro e o fora da medida socioeducativa de internação: uma abordagem semiótico-cultural do desenvolvimento. (Tese de Doutorado não publicada, Instituto de Psicologia, Universidade de Brasília, DF).

Marsico, G. (2016). The borderland. Culture \& Psychology, 22(2), 206-215. Doi: https://doi. org/10.1177/1354067X15601199

Mattos, E. (2013). Desenvolvimento do self na transição para a vida adulta: um estudo longitudinal com jovens baianos. (Tese de Doutorado Não-Publicada, Programa de Pós-Graduação em Psicologia, Universidade Federal da Bahia, Bahia).

Minayo, M. S. (2006). Violência e Saúde. Rio de Janeiro: FIOCRUZ.

Pais, J. M. (1990). A construção sociológica da juventude: alguns contributos. Análise Social, $X X V(105-106), 139-165$.

Paiva, I., Lopes de Oliveira, M.C.S., \& Colaço, V. (2019). Adolescentes em conflito com a lei: entre o prescrito legal e a prática social. Em V. Colaço, I. Germano, L. Miranda, J.P. Barros (Orgs). Juventudes em movimento: experiências, redes e afetos (pp. 160-176). Fortaleza: Expressão Gráfica.

Pedersen, J. R. (jan-jun de 2009). Vitimização e vitimização de crianças e adolescentes: expressão da questão social e objeto de trabalho do Serviço Social. Revista Textos e Contextos, 8(1), 104-122.

Pereira, S. E. (2019). Redes sociais de adolescente em contextos de vulnerabilidade social e sua relação com os riscos de envolvimento com o tráfico de drogas. Brasília: UnB.

PNUD (Programa das Nações Unidas para o Desenvolvimento) (2018). Indicadores e Índices de
Desenvolvimento humano: Atualização Estatística 2018. New York: United Nations Development Programme.

Roncancio-Moreno, M. R., \& Branco, A. (2014). Desenvolvimento de si em crianças na perspectiva dialógico-cultural. Psicologia em Estudo, 19(4), 599-610. Doi: http://dx.doi. org/10.1590/1413-73722189303

Rossetti-Ferreira, M., K., A., \& Silva, A. (2000). Uma perspectiva teórico-metodológica para análise do desenvolvimento humano e do processo de investigação. Ribeirão Preto: USP.

Salgado, J., Gonçalves, M. (2007). The dialogical Self: Social, personal, and (un)conscious. Em, J. Valsiner, A. Rosa (Eds.). The Cambridge Handbook of Sociocultural Psychology (pp. 608-621). Cambridge, UK: Cambridge University Press.

Salvatore, S. (2014). The mountain of cultural psychology and the mouse of empirical studies. Methodological considerations for birth control. Culture \& Psychology, 477-500.

Sato, T., \& Valsiner, J. (2010). Time in life and life in time. Between experiencing and accounting. Ritsumeikan Journal of Human Sciences, 20(1), 79-92.

Sposito, M. P. (2005). Indagações sobre as relações entre juventude e a escola no Brasil: institucionalização tradicional e novos significados. Estudios sobre Juventud, 9, 201-227.

Valsiner, J. (2012). Fundamentos de uma psicologia cultural: mundos da mente, mundos da vida. (A. C. Bastos, Trad.) Porto Alegre: Artmed.

Valsiner, J. (2016). Imagining a new science of psychology. In L. Tateo (Ed.), Giambattista Vico and the New Psychological Science (pp. vii-ix). Abingdon: Routledge.

Wagoner, B., \& Brescó, I. (2016). Conflict and memory: The past in the present. Peace and Conflict: Journal of Peace Psychology, 22(1), 3-4. Doi: http://dx.doi.org/10.1037/pac0000147

Yokoy de Souza, T. (2007). Um estudo dialógico sobre institucionalização e subjetivação de adolescentes em uma casa de semiliberdade. 
(Dissertação de mestrado, Instituto de Psicologia. Brasília, UnB).

Zittoun, T. (2009) Dynamics of life-course transitions: A methodological reflection. In J. Valsiner, P. Molenaar, M. Lyra, \& N. Chaudary (Ed.). Dynamics process methodology in the social and developmental sciences (pp. 405-430). New York, NY: Springer.

Zittoun, T., Valsiner, J., Vedeler, D., Salgado, J., Gonçalves, M., \& Ferring, D. (2013). Human Development in the life course. Melodies of living. Cambridge, UK: Cambridge University Press.

Recebido: junho 4, 2019

Aprovado: agosto 17, 2019 